\title{
The relationship between Birth Order and Sales Person's performance in Ghana.
}

\author{
Edward Markwei Martey, Patricia Crentsil
}

Koforidua Technical University, Ghana. Faculty of Business and Management Studies

edmarkwei@yahoo.com

\begin{abstract}
s
The aim of the study is to predict the impact of birth order effect on sales person's performance. The main objective is to investigate the relationship between birth order; (firstborns, middle children, lastborns, and only children) on sales person's performance. Besides, it also aimed to examine the relationship between personality and sales person's performance. The target population of the study comprised of sales person 's shared mean age of 21.0 years (Standard Deviation $=1.93$ ) and have worked as sales person for a minimum of three years. Participants were recruited from the Greater Accra Region of Ghana. The study adopted purposive sampling technique to select the sales person and a total of 788 out of the 900 participants returned their questionnaires. A linear regression equation was employed to measure how birth order predicts sales person's performance, with birth order (firstborns, middle children, lastborns, and only children) as the predictor variables and sales person's performance as the criterion variable. Results indicated that a participant of different birth positions does not differ significantly in terms of sales person's performance.
\end{abstract}

Keywords; Birth Order; sales person’s Performance; firstborn; Extraversion; Middle children

\section{Introduction}

Alfred Adler is among the first theorists to suggest the effect of birth order on personality (Adler, 1931). He explained that birth order impacted on the individual's style of life, influences manner in which an individual deals with tasks of friendship, love, and work.

Eckstein \& Aycock et al., (2010), defines birth order as a science of understanding a person's place in a family. "It is not, of course, the child's number in the order of successive births which influence his or her character, but the situation into which he or she is born and the manner he or she interprets his or her role as a child or his or her interactions with others". Child's personality is influenced mainly by his or her chronological place in the family because parents have a tendency of treating children differently based on the order of their birth (Isaacson, 2004)

In the submission of Kalkan (2008) he makes it clear that there are two different types of birth order: actual and psychological. He explains actual birth order as the order in which a person comes into the world such as: first child born, only child born, second child born, or last child born. Actual birth order is associated with child's personality traits, behavior, attitude and interest. According to Leman (2009) birth order is categorized into four basic positions of a child: oldest, middle, youngest, and only child. This shapes the manner in which parents and siblings behave.

Many researches, have examined the impact of birth order on sales personnel's performance. According to the findings of, Black,et al (2007) and Bjerkedal, et al. (2007), there is a strong and significant effect of birth order on sales person's performance in Norway. Contrary, Rodgers et al. (2000, 2001) disagree with the existent of relationship and criticized studies for confounding "within-family" and "betweenfamily" that birth order shapes sales person's performance. Whichman et al (2006) insist that the relationship only arises between families and disappears within the family. 
Spring (2003) argues that there is no relationship between birth order and sales person's performance, and that big families have the tendency to produce lower IQ children. To our best knowledge, no study has examined the effect of birth order on sales person's performance in Ghana. This study therefore examines the effect of birth order on sales person's performance in Ghana.

Adler observed that the personalities of the oldest, middle, and the youngest child in a family were not the same because of distinctive experiences that each child has as a member of a family. The distinctive experiences and birth order in the family are important and could affect development in critical ways (Adler, 1992b).

Kluger (2011) argues that first child is conscientious and exhibits a general sense of responsibility and a tendency to follow through with whatever they may have started. First born children have a tendency to excel academically than their other siblings. First born children assist to mentor and teach their younger siblings as they come along and are caretakers. First child learns from adults, whom they see as big perfect people who do everything correctly. This led to the first hypothesis of the study.H1.there is a positive relationship between first child and sales person's performance.

Middle born children come into the world with a sibling already ahead of them. Middle children look at their older sibling and feel as if they are in a race with the first born (Kalkan, 2008). Middle children are both the teacher and the student and the babysitter and babysat (Kluger, 2011).Most middle born children compete with their older born sibling, this causes sibling rivalry among the two children (Leman, 2009). Middle born children always want to acquire rewards and recognition, avoid pain and danger, and get even (Leman, 2009).

This led to the second hypothesis of the study.H2.there is a positive relationship between middle- child and sales person's performance

Last born children normally stay longer with the parents as their older siblings are in school or have grown up and moved out of the house (Salmon, 2003).Last born children look up to their elder siblings as the pacesetters in the family. They get most of their instructions from their older brother and sister. First born children sometimes take up the role of the assistant parents to the last born children. The last born children are unable to take that role of the assistant parent and develop new talents. (Badger\&Reddy, 2009). This led to the third hypothesis of the study.H3.there is a positive relationship between last born child and sales person's performance

The only child hates to admit when they are wrong and do not accept criticism well. They tend to follow the patterns established by their parents (Leman, 2001). According to Leman, (2009) "The only child has difficulties with every independent activity and sooner or later they become useless in life"

The only child may appreciate the attention that they receive from the parents who may cause them to feel dependent or entitled when outside of their family atmosphere (Stewart et al 2001). This led to the fourth hypothesis of the study.H4.there is a positive relationship between only child and sales person's performance

\section{Methodology}

The study used both primary and secondary data. The study adopted purposive sampling technique to select institution and select sales person. The study used 197 firstborns, 197 middle children, 197 lastborns, and 197 solely children from tertiary institutions in Ghana. Participants' age ranged from 16 to 25 years where the mean age was 21.0 years, with a standard deviation of 1.93 . There were $398(50.5 \%)$ and 390 $(49.5 \%)$ males and females respectively. The target population comprised sales person who have worked for a minimum of three years in the Greater Accra Region of Ghana.

Performance of participants were scored according to the; lead response time, rate of contact, rate of follow up contact, sales follow-up, opportunity-to-Win Ratio and sales over a period of one year.

Total points of participants' represented their performance. The higher the total points, the better the sales performance of the participants.

Data was collected through the use of questionnaire. The questionnaire was divided into five sections. Section A elicited general and biographical information about respondents, section $B$ elicited information on birth order of respondents and section $\mathrm{C}$ sought information on sales person's performance of respondents. Participants were required to rate on a 5-point Likert scale, which ranged from strongly disagree to strongly agree the posited questions.

The following statistics were computed with the aid of SPSS: descriptive statistics to have clear picture of the study 
variables and regression analysis to measure the effect of independent variable on dependent variable.

\section{Result and Discussion}

The mean and standard deviation of the entire construct have been presented in Table 1 . The result revealed that the mean scores for the first-born child, middle-born child, lastborn child and only-born child are 3.321, 4.213, 3.454 and 3.412 respectively. The values are greater than 1 , this shows that constructs are worthy for the study. Similarly, the mean values for sales person's performance is (4.321), which also indicates that the construct is worth studying.

Table 1

Descriptive Statistics

\begin{tabular}{lcccc}
\hline Construct & Min & Max & Mean & St.Deviation \\
\hline Firrst Child (FC) & 1 & 7 & 3.321 & 0.421 \\
Middle Child (MC) & 1 & 7 & 4.213 & 0.332 \\
Last born (LB) & 1 & 7 & 3.454 & 0.253 \\
Only Child (OC) & 1 & 7 & 3.412 & 0.253 \\
Sales Persons & 1 & 7 & 4.321 & 1.452 \\
Performance(SPP) & & & & \\
\hline
\end{tabular}

\subsection{Inferential Statistics}

In this section the results of the inferential statistical table used in the study are presented. The result of the Pearson correlation co-efficient is represented in Table 2. The correlation coefficients of FC, ML, LB, and OC are 0.021, 0.034, 0.011 and 0.012 respectively. These are not significant since their $\mathrm{p}$-values are greater than 0.05 . This result shows that FC, ML LB, and OC have weak significant impact on SPP.

Table2

Correlation Matrix

\begin{tabular}{l|c|c}
\hline \multirow{2}{*}{} & \multicolumn{2}{|c}{} \\
\cline { 2 - 3 } & $\begin{array}{l}\text { Pearson } \\
\text { correlation }\end{array}$ & $\begin{array}{l}\text { significance } \\
0.05 \\
\end{array}$ \\
& & 0.221 \\
First child & 0.021 & 0.134 \\
Middle child & 0.034 & 0.231 \\
Last child & 0.011 & 0.121 \\
Only child & 0.012 & \\
\hline
\end{tabular}

The value for the $\mathrm{R}$-squared in Table 3 is 0.131 which indicates that $13.1 \%$ of the variation in the dependent variable is explained by the independent variables of the model. The $86.9 \%$ variation in the dependent variable remains unexplained by the independent variables of the study.

Table 3

Goodness of Fit birth order and sales person's performance

$\begin{array}{lllc}\text { Model } & \mathrm{R} & \mathrm{R} \text { square } & \text { Adjusted R Square } \\ & 0.131 & 0.0172 & 0.121\end{array}$

The value for the F-statistic in Table 4 is 4.38 and is Significant $(p<0.01)$ endorsing the validity and stability of the model is relevant for the study. The other diagnostics suggest that the FC, MC, LC and OC have poor significant relation with sales person's performance.

Table 4

Pooled Ordinary Least Square Dependent Variable

\begin{tabular}{lc}
\hline Construct & Coefficients \\
\hline Firrst Child (FC) & $-0.012^{* * *}$ \\
Middle Child (MC) & $-0.154^{* *}$ \\
Last born (LB) & $-0.021^{* * *}$ \\
Only Child (OC) & $-0.031^{*}$ \\
Adjusted R- Square & 0.431 \\
F-Statistics & $4.38^{*}$ \\
\hline * ** and *** shows correlation is significant at the 0.01, 0.05 and \\
0.09 level.
\end{tabular}

The test to detect multicollinearity (variance inflation factor) was performed to support the validity of the regression results. In case of VIF, if the result is below 10 and Tolerance near to zero suggest no multicollinearity (Gujrati, 2003).

In Table 5, results of Variance Inflation Factor (VIF) and tolerance factor is reasonably good. The values of variance inflation factor for the variables in the model ranges from 1.322 to 4.321 for first child to only child suggesting the absence of multicollinearity among the variables of the model.

Table 5

Values of Tolerance and Variance Inflation Factor (VIF) for sales personnel's performance

Construct Tolerance Variance Inflation 


$\begin{array}{lll}\text { First child } & 0.467 & 0.681 \\ \text { Middle child } & 1.456 & 1.322 \\ & & \\ \text { Last child } & 0.734 & 2.523 \\ \text { Only child } & 0.534 & 4.321\end{array}$

\subsection{Robustness Tests:}

Robustness test used in this study is the test for endogeneity. This test is performed to make the results of the study robust. Where such a relationship exists it raises the possibility of endogeneity in our model. The result is presented in Table 6.

Table 6

Pooled least square endogeneity test dependent variable: sales person's performance

\begin{tabular}{ll}
\hline Construct & Sales Person's performance \\
\hline Constant & $-0.012(1.021)$ \\
Firrst Child (FC) & $-0.1023(-0.432)$ \\
Middle Child (MC) & $0.143(1.321)^{* *}$ \\
Last born (LB) & $0.212^{* * *}(1.523)$ \\
Only Child (OC) & $0.113^{* * *}(1.321)$ \\
Residua & $0.022(0.321)$ \\
R square & 0.142 \\
Adjusted R- Square & 0.02016 \\
F-Statistics & $104.8^{*}$ \\
\hline
\end{tabular}

Notes: The values of the coefficients are in the first row. Below are the values for t-statistics in parenthesis. *** and *** Represents the significance of available at 1, 5 and $10 \%$ significance level.

The empirical results support all hypotheses H1, H2, H3 and H4. The empirical results found no significant relationship among first child, middle child, last child and only child on sales person's performance. This means that birth order does not influence the sales person's performance. The relationship between the independent variable (first child, middle child, last child and only child) and the dependent variable (sales person's performance) proved to be insignificant. This finding is supported by the study conducted by Steelman and Powell's (1985) who could not find any relationship between birth order and sales person's performance. Their finding is congruent with the study conducted by Sun $\mathrm{Ha}$ and Lian Tam (2011) whose findings concluded that there is no significant correlation between the variables. On the contrary, a study by Holzs et al (2011) from Washington
University concluded that "those born earlier perform better in school."

However, a study conducted by Onabarniro et al (2010) studied the relationship between birth order and sales person's performance which indicates a positive significant relationship between last child and low sales person's performance. Liaquat and Ali Khan (2012) studied the impact of birth order on sales person's performance and hypothesized that there is no impact of birth order on the sales person's performance tested.

A study conducted by Harris (1998) reveals that birth order may not have an impact on sales person's performance. A similar concept to Adler's work, Zajonc found that birth order and family size have a significant impact on adolescent's intellectual performance, which he calls 'confluence model'. Belmont and Marolla (1973) found a significant effect of birth order on intelligence. According to Marjoribanks (2003) birth order have small but significant associations with sales personnel's aspirations.

\section{Conclusion}

Birth order positions influence the achievement and motivation of sales person in a way. There is a need to identify strengths and weaknesses of each birth order position. Beside understanding birth order, individuals can also understand not only themselves more comprehensively, but also those with whom they come in direct contact. As such, this knowledge can be considered useful in the areas of marketing.

Every child is unique in a constellation of traits and life experience, the key is for marketing mangers to discover as much as possible about the child in order to help them flourish. A future research on birth order and behavioural traits on sales person, performance is recommended.

\section{References}

Adler A. (1931) What Life Should Mean to You. What Life Should mean to you (1931) publ. Unwin Books, Chapter 2 reproduced here. Available athttps://www.marxists.org/reference/subject/phi losophy/works/at/adler.htm

Adler, A. (1992). Position in family constellation influences life style. New Ed. In L. Baruth \& D. 
Badger, J., \& Reddy, P. (2009). The effects of birth order on personality traits and feelings of academic sibling rivalry. Psychology Teaching Review,15, 45-54

Belmont, L., \& Marolla, F. A. (1973). Birth Order, Family Size, and Intelligence A study of a total population of 19-year-old men born in the Netherlands is presented. Science, 182(4117), 1096-1101. Accessed from http://science.sciencemag.org/content/182/4117/ 1096

Eckstein, D., Aycock, K. J., Sperber, M. A., McDonald, J., Van Wiesner III, V., Watts, R. E., \& Ginsburg, P. (2010). A review of 200 birth-order studies: Lifestyle characteristics. The Journal of Individual Psychology, 66(4), 408-434. Available at http://www.alfredadler.edu/sites/default/files/Mu rphy_MP_2012.pdf

Gujarati, D. (2003). Basic Econometrics. New York: McGraw-Hill.

Ha, T. S., \& Tam, C. L. (2011). A study of birth order, academic performance, and personality. In International Conference on Social Science and Humanity, IPEDR (Vol. 5, No. 1, pp. 28-32). http://ipedr.com/vol5/no1/7-H00037.pdf

alDetailedMesh?docid=15337812-201001201101260054-201101260054-360-363

Rodgers, A., Walker, N., Schug, S., McKee, A., Kehlet, H., Van Zundert, A., \& MacMahon, S. (2000). Reduction of postoperative mortality and morbidity with epidural or spinal anaesthesia: results from overview of randomized trials. Bmj, 321(7275), 1493.

Rodgers, J. L. (2001). What causes birth orderintelligence patterns? The admixture hypothesis, revived. American Psychologist, 56 (6-7), 505.

Salmon, C. (2003). Birth order and relationships: Family, friends, and sexual partners. Human Nature, 14(1), 73-88.
Harris, J. R. (2011). The nurture assumption: Why children turn out the way they do.

Isaacson, C. (2004). The birth order effect for couples: How birth order affects your relationships and what you can do about it. Gloucester, MA: Fair Winds Press.

Kalkan, M. (2008). The relationship of psychological birth order to irrational relationship beliefs. Social Behavior and Personality, 36(4), 455-466.

Leman, K. (2009). The birth order book: Why you are the way you are. Grand Rapids, MI: Revell.

Leman, K. (2001). The birth order connection. Grand Rapids, MI: Revell.

Maejoribanks, K. (2003). Birth order, family environments, academic and affective outcomes. Psychological reports, $92(3 \mathrm{c})$, 1284-1286.

Onabarniro, A. A., Ositoye, A., \& Adeyemi, M. (2010). Influence and Relationship of Birth Order and Secondary School Students. Academic Leadership Journal, 8(4), 360-363. http://www.airitilibrary.com/Publication

Stewart, A.E., Stewart, E.A., \& Campbell, L.F. (2001). The relationship of psychological birth order to the family atmosphere and to personality. The Journal of Individual Psychology, 57(4), 363-388.

Wichmann, F.A., Sharpe, L.T., \& Gegenfurtner, K.R. (2002). The contributions of color to recognition memory for natural scenes. Journal of Experimental Psychology: Learning, Memory, and Cognition, 28, 509_ 520 . 